\title{
More than half the women with a history of psychosis have a psychiatric episode in the first year after childbirth
}

Howard LM, Goss C, Leese M, et al. The psychosocial outcome of pregnancy in women with psychotic disorders. Schizophr Res 2004;71:49-60.

\section{What is the psychiatric outcome of childbirth in women with a history of psychosis? Are women with a history of psychosis more likely to have postnatal depression than women with no history of psychosis?}

\section{METHODS}

$-$

Design: Retrospective cohort study.

2.2. Setting: UK primary care data from the General Practice

Research Database between 1996 and 1998

o Population: 194 women aged 15-44 with a diagnosis of psychotic disorder or a prescription for a neuroleptic depot, an atypical antipsychotic, or lithium. The study also examined 781 age matched women without a history of psychosis.

Prognostic factors: Demographic details, substance misuse and smoking, medical and psychiatric history, and prescribed drugs during pregnancy.

Outcomes: Psychiatric episode (psychiatric admission, new psychiatric problems, psychiatric referral).

Follow up period: 3 months and 1 year

\section{MAIN RESULTS}

Prognosis: Women with a history of psychosis are at high risk of a psychiatric episode in the first year after childbirth (see table). Psychosis as a risk factor for post-natal depression: Women with a history of psychosis are more likely to have postnatal depression compared with age matched controls in the first year after childbirth (RR adjusted for active illness $2.04,95 \%$ CI 1.45 to 2.88 ).

\begin{tabular}{lll} 
Table Psychiatric episodes after childbirth \\
\hline & $\begin{array}{l}\text { History of psychosis } \\
\text { (n= 194) }\end{array}$ \\
\cline { 2 - 3 } & Three months & One year \\
Type of psychiatric episode & $51(26 \%)$ & $73(38 \%)$ \\
\hline $\begin{array}{l}\text { Non-psychotic depression/ } \\
\text { anxiety }\end{array}$ & $15(8 \%)$ & $19(10 \%)$ \\
$\begin{array}{l}\text { Affective psychosis } \\
\text { Puerperal psychosis }\end{array}$ & $15(8 \%)$ & $17(9 \%)$ \\
$\begin{array}{l}\text { Schizophrenia } \\
\text { Schizo-affective psychosis }\end{array}$ & $2(3 \%)$ & $9(5 \%)$ \\
$\begin{array}{l}\text { Psychosis not otherwise } \\
\text { specified }\end{array}$ & $3(2 \%)$ & $2(1 \%)$ \\
Unclear diagnosis & $2(1 \%)$ & $5(2 \%)$ \\
\hline
\end{tabular}

For correspondence: Louis Psychiatry, Health Services Research Department, Institute of Psychiatry, London SE5 8AF, UK; spjelmh@iop.kcl.ac.uk

Sources of funding: Wellcome Trust Health Services Research training fellowship.

\section{CONCLUSIONS}

Women with a history of psychosis are at high risk of a psychiatric episode in the first year, and are more likely to have postnatal depression compared with women without a history of psychosis. In women with a history of psychosis, preventive psychiatric services may be warranted for at least a year after childbirth.

\section{NOTES}

This study used retrospectively analysed information from a database, and did not verify the data with individual assessments.

\section{Commentary}

linicians have traditionally focused their attention on the obstetric outcome of pregnancy in women with mental illness. ${ }^{1}$ However, Howard et al add to previous work ${ }^{2}$ analysing the psychosocial outcome of pregnancy in this particular population.

They make a number of interesting observations that have clinical implications for practice: (1) regardless of the severity of mental illness, only $25 \%$ of mothers took psychotropic medications during pregnancy; (2) $55 \%$ of women with schizophrenia relapsed within one year after parturition; surprisingly, women with schizophrenia also appear to be at high risk of developing postpartum non-psychotic affective disorders; (3) all the babies needing social services care were born to mothers affected by schizophrenia and related disorders; and (4) the only significant predictor of parenting difficulties was recent contact with psychiatric services.

Women with severe mental illness avoid services during pregnancy for fear of losing custody of their babies. The fact that women with poor psychosocial pregnancy outcome are more likely to be in contact with psychiatric services could be due to the worsening of their psychotic symptoms. The percentage of women receiving treatment rises to $70 \%$ after pregnancy.

Unfortunately, no correlation has been made between pregnancy outcome and dosage maintenance, reduction, or discontinuation of antipsychotic treatment during pregnancy. This key factor associated with the relapse of psychotic disorder, ${ }^{34}$ and consequently with poor pregnancy outcome, ${ }^{5}$ requires investigation.

In clinical practice, preliminary pharmacological treatment of severe psychiatric disorders is often necessary to obtain rapid clinical remission, therefore enabling the use of subsequent alternative interventions, such as socio-educational and rehabilitation programmes. During this phase of pharmacological remission, a psychosocial approach could successfully aid a sound mother-infant relationship.

Salvatore Gentile, MD Mental Health Center n. 4, Department of Mental Health, ASL Salerno 1,

1 Nillsonn $E$, Lichtenstein $P$, Cnattingius S, et al. Women with schizophrenia: pregnancy outcome and infant death among their offspring. Schizophr Res 2002;58:221-9.

2 Howard LM, Thornicroft G, Salmon M, et al. Predictors of parenting outcome in women with psychotic disorders discharged from mother and baby units. Acta Psychiatr Scand 2004;1 10:347-55.

3 Gilbert PL, Harris MJ, McAdams LA, et al. Neuroleptic withdrawal in schizophrenic patients: a review of literature. Arch Gen Psychiatry 1995;52:137-88.

4 Baldessrini RJ, Viguera AC. Neuroleptic withdrawal in schizophrenic patients. Arch Gen Psychiatry 1995;52:189-92.

5 Gentile S. Clinical utilization of atypical antipsychotics in pregnancy and lactation. Ann Pharmacother 2004;38:1265-71. 